\title{
Alansal/Yersel Lazer Tarayıcıların Arkeolojik Mekânların Fiziki Özelliklerinin Tespitinde Kullanılması: Kibrya Antik Kenti Odeon Yapısı Sahne Duvarı Örneği
}

\author{
Sualp DENIZ1 ${ }^{1}$, Serkan ÖKTEM ${ }^{1 *}$, İbrahim KIRBAŞ ${ }^{1}$, Düzgün TARKAN ${ }^{2}$ \\ ${ }^{1}$ Mehmet Akif Ersoy Üniversitesi, Teknik Bilimler Meslek Yüksekokulu, Burdur \\ ${ }^{2}$ Mehmet Akif Ersoy Üniversitesi Fen Edebiyat Fakültesi, Burdur \\ Geliş Tarihi (Received): 24.08.2017, Kabul Tarihi (Accepted): 11.10.2017 \\ $\square$ Sorumlu Yazar (Corresponding author*): serkanoktem@mehmetakif.edu.tr \\ (C) +902482134558 皿 +902482134598
}

ÖZ

Arkeolojik alanlarda yapıların mimari rölöve çizimleri, görünüş ve kesitlerinin çizimi mimari eserlerin belgelendirilmesi ve restorasyon projelerinde en önemli aşamalardan biridir. Bu amaçla çoğunlukla şerit metre, su terazisi, gönye, şakul, profil tarağı, jalon, prizma, mira vb. gibi mekanik ölçü aletleri kullanılmaktadır. Ancak bu ölçü aletleri ile yapılan ölçümler çoğu zaman büyük hatalar içermekte, yapının strüktürel özellikleri büyük hata payları ile elde edilmektedir. Lazer tarayıcılardan önce kullanılan nivo, takeometre gibi harita mühendislerinin kullandığı dijital teknolojiler bahsedilen hata paylarını büyük ölçüde azaltsa da yapının üç boyutlu modellemesini mümkün kılamamıştır. Oysa yersel lazer tarayıcılar taradıkları objeyi üç boyutlu olarak modellemekte, dolayısı ile yapının farklı açılardan görüntülenerek plan, görünüş ve kesitlerinin çizimi son derece hızlı yapılabilmektedir. Bu çalışmada yersel lazer tarayıcısı ile Kibrya antik kenti yapılarından Odeon Binasının sahne duvarının mekânsal özelliklerinin elde edilerek rölövesinin çizimine bir çalışma esas alınmıştır.

Anahtar Kelimeler: Arkeoloji, lazer tarama, rölöve

\section{Use of Areal/Terrestrial Laser Scanners in Detecting the Physical Features of Archaeological Sites: Stage Wall Sample at the Odeon of Kibrya Ancient City}

\begin{abstract}
The architectural drawings of the buildings in the archaeological sites, the drawings of the views and sections are the most important steps in the documentation of the architectural works and the restoration projects. For this purpose, we mainly use tape meters, water scales, miter, plumb, profile comb, range-rod, prism, surveying rod etc. mechanical measuring instruments are used. However, measurements made with these measuring instruments often contain major errors, and the structural characteristics of the structure are obtained with large errors. The digital technologies used by the map engineers such as dumpy level and takeometre, which were used before the laser scanners, greatly reduce the mentioned error rates, but they have not made possible the three-dimensional model of the structure. However, the terrestrial laser scanners model the object they are scanning in three dimensions, so that the drawing of the plan, appearance and cross-sections can be made very fast by displaying the structure from different angles. In this study, a study was made to draw the spatial characteristics of the stage wall of the Odeon Building from the Kibrya ancient city structures with the terrestrial laser scanner and to draw the survey report.
\end{abstract}

Keywords: Archaeology, laser scanning, surveying 


\section{Giriş}

Burdur'a bağlı Gölhisar İlçesi'nin hemen kuzeybatı kenarındaki tepelerde konumlanan Kibyra antik kenti, antik dönemde Likya, Karya, Pisidya ve Frigya kültür bölgelerinin kesişme noktasında; kuzeyi güneye ve doğuyu batıya bağlayan ticaret yollarının tam merkezinde konumlanır. Bugün de Gölhisar, Antalya - Denizli / Burdur - Fethiye karayollarının birleştiği bir kavşak noktasıdır. Bu konumuyla Kibyra antik kenti, Burdur'a 120 km, Denizli'ye 105 km, Antalya'ya 135 km ve Fethiye'ye $110 \mathrm{~km}$. mesafe uzaklıktadır (URL-1, 2017).

Kentin bugün görülebilen tüm mimari kalıntıları Roma İmparatorluk Dönemi'ne aittir. Roma İmparatorluk Dönemi'nde, kendisine yaklaşık 25 kentin bağlı olduğu "Kibyra Conventusu" adı altında, Asia Eyalet Valisi'nin yargı merkezi olmuştur. M.S. 23 yılında meydana gelen büyük bir deprem sonucunda yerle bir olan kent, Roma Imparatoru Tiberius'un vergi affı getirmesiyle yeniden inşa edilebilmiştir. Kibyra özellikle M.S. 1-3. yüzyıllarda en parlak ve zengin dönemini yaşamıştır (URL-2, 2017).

Kibyra, Bubon, Balboura ve Oinoanda'dan oluşan dörtlü ortak meclisin, "Kabalis Tetrapolisi" nin, yörenin politik tarihinde önemli bir yere sahip olduğu bilinmektedir. Antik kaynaklar, söz konusu birliğin Roma generali Murena tarafından dağıtıldığını belgelemektedir. Nitekim bu tarihten sonra Kibyra, Asia Eyaleti'ne ve diğer üç kent Likya Birliği'ne dahil edilmiştir. Başkentliğini Kibyra'nın üstlendiği tetrapolisin toplantı yerinin de yine bu kentte, yöre sakinlerince "yedi delik" olarak anılan ve büyüklüğüyle etkileyen "Bouleuterion" olduğu bellidir (Ekinci ve ark., 2006).

Nitekim bugün büyük oranda sağlam durumdaki yapı ve çevresini kapsayan sistematik çalışmalarla konunun bilimsel tartışmalara açılması öngörülmektedir (URL-1, 2017).

13/04/2016 tarihinde UNESCO Dünya Mirası Geçici Listesine alınan Kibrya antik kentinde bulunan yapıların belgelendirilmesi daha da önem kazanmıştır (URL-3, 2017).

Bu çalışmamızda Burdur ili Gölhisar ilçesinde bulunan Kibrya antik kentinde yer alan Odeon yapısına ait sahne duvarının fiziki özelliklerinin yersel lazer tarayıcısı ile tespit edilmesi esas alınmıştır. Bu amaçla Faro Focus 3d X330 Lazer tarayıcısı, Faro Scene ve AutoDesk ReCap yazımları kullanılmıştır. Focus3D X330 serisine ait lazer tarayıcımızın küçük ve hafif olması çalışmamızın hızını önemli ölçüde artırmıştır (Tablo 1).
Tablo 1. Focus3D X330 lazer tarayıcı özellikleri (URL4, 2017).

\begin{tabular}{|c|c|}
\hline Netlik Aralığı & $\begin{array}{l}\text { 614metrede } 122-488 \mathrm{Kpts} / \text { Saniye, } \\
307 \text { Metrede } 976 \mathrm{kpts} / \text { Saniye }\end{array}$ \\
\hline $\begin{array}{l}\text { Mesafe Focus X } \\
330\end{array}$ & $\begin{array}{l}\text { Kapalı veya açık alan ve \%90'a } \\
\text { kadar yansıtıı yüzeyde normal } \\
\text { gelis açısında } 0.6 \mathrm{~m}-330 \mathrm{~m} \text { arası }\end{array}$ \\
\hline Ölçümleme Hızı & $\begin{array}{l}122.000 / 244.000 / 488.000 / 976.000 \\
\text { nokta/Saniye }\end{array}$ \\
\hline Mesafe Hatası & $\pm 2 \mathrm{~mm}$ \\
\hline Çözünürlük & Renkli 70 Megapiksele kadar \\
\hline $\begin{array}{l}\text { Dinamik Renk } \\
\text { Özelliği }\end{array}$ & Otomatik parlaklık ayarlama \\
\hline Paralaks & Ortak açılı tasarım \\
\hline $\begin{array}{l}\text { Görünüş Alanı } \\
\text { (Dikey/Yatay) }\end{array}$ & $300^{\circ} / 360^{\circ}$ \\
\hline $\begin{array}{l}\text { Adım Boyu- } \\
\text { tu(Dikey/Yatay) }\end{array}$ & $\begin{array}{l}0.009^{\circ}\left(360^{\circ} \mathrm{de} 40.960 .3 \mathrm{D} \text { piksel }\right) / / \\
0.009^{\circ}\left(360^{\circ} \mathrm{de} 40.9603 \mathrm{D} \text { Piksel }\right)\end{array}$ \\
\hline $\begin{array}{l}\text { Max.Dikey Ta- } \\
\text { rama Hızı }\end{array}$ & Dakikada 5.820 Devir veya $97 \mathrm{HZ}$ \\
\hline Lazer Sınıfı: & Lazer sınıfı 1 \\
\hline Dalga Boyu & $1550 \mathrm{~nm}$ \\
\hline GPS & Entegre GPS alıcıSı \\
\hline
\end{tabular}

\section{MATERYAL VE YÖNTEM}

Arkeolojik alanlardaki yapıların belgelendirilmesi, restore edilmesi, güçlendirilmesi gibi birçok faaliyette öncelikle yapının rölövesinin çizilmesi gerekmektedir. Rölöve çizimleri yapının tasarım detaylarını tam olarak anlatmalı, ileriki aşamalarda kullanılabilecek nitelik ve ölçekteki çizimsel bir belge olma özelliğini içermelidir. Rölöve çizimlerinde plan, kesit ve cepheler üzerinde alınan tüm ölçüler, kotlar düzenli bir biçimde gösterilir. Ölçülerin kolay anlaşılabilir biçimde olması, yapının referans noktalarını tanımlaması gerekmektedir. Yapının yapım tekniğini, özel mekân düzenini, strüktürel tasarımını daha iyi açıklayabilmek amacıyla gerektiğinde izometrik perspektifler çizilir. Genellikle rölöve çizimleri yapı üzerinden şerit metre, su terazisi, gönye, şakul, profil tarağı, jalon, prizma, mira vb. gibi mekanik ölçü aletleri ile ölçü almak suretiyle çizilir. Son derece uzun ve meşakkatli olan ölçümler sonrasında çizilen rölöve ile yapının gerçek ölçüleri eşleştirildiğinde büyük farklılıkların olduğu bilinen bir gerçektir. Buna karşılık lazer tarayıcılar bu hata paylarının neredeyse yok denecek seviyelere indirmektedir. Lazer tarayıcıların arkeolojik alanlarda kullanımı eserlerin belgelendirilmesinde ve rölövelerinin çizilmesinde son derece hızlı ve gerçekçi çözümler üretmektedir.

Yersel lazer tarayıcıların çalışma prensibi kaynaktan gönderilen lazer ışınının çıkışı ve geri dönüşü arasında geçen sürenin kayit edilmesi ve bu şekilde mesafesinin ölçülmesine dayanmaktadır (Boehler ve Marbs, 2003).

2015-2016 yılları arasında gerçekleştirilen ve Batı Akdeniz Kalkınma Ajansının desteklediği "Burdur İli Ar- 
keolojik ve kültürel miraslarının lazer teknolojisi ile 3 boyutlu modellemesi ve sanal 3D müze oluşturulması" projesi ile temin edilen Focus3D lazer tarayıcımız, 330 metre yarıçapındaki bir alanı $1550 \mathrm{~nm}$ dalga boyunda Lazer ışınları ile tarama imkânı sunmaktadır. Cihazımızın netlik aralığı 614 metrede 122-488 Kpts/Saniye, 307 Metrede $976 \mathrm{kpts} /$ Saniyedir. Tarayıcının etkili mesafesi kapalı veya açık alanda ve \%90'a kadar yansıtıcı yüzeyde normal geliş açısında $0.6 \mathrm{~m}-330 \mathrm{~m}$ arasındadır. Lazer tarayıcımız elde ettiği nokta bulutları üzerine 70 megapiksel ölçeğinde çekmiş olduğu fotoğrafları giydirerek gerçekçi bir görünüm sunmaktadır. Aynı zamanda üzerine entegre şekilde bulunan GPS alıcısı ile tarama yapılan istasyona ait koordinat bilgilerini hafızasında saklamaktadır.

\section{BULGULAR VE TARTIŞMA}

Çalışmamızda öncelikle 20 farklı istasyondan tarama işlemi gerçekleştirilmiştir. Her bir tarama istasyonu bir önceki ve bir sonraki tarama istasyonlarının göremeyeceği yüzeyleri görür nitelikte belirlenmiştir. Taramalar sırasında farklı istasyonlardan elde edilen nokta bulutlarının bilgisayar ortamında birleştirilmesinde referans olarak kullanılması amacıyla "faro referans küreleri" kullanılmıştır.

Her bir tarama istasyonunda 17 dakikalık tarama işlemi gerçekleştirilmiş ve bu işlem 20 farklı istasyonda tekrar edilmiştir. Elde edilen veriler Faro Scene 5.5.0 programına aktarılmıştır. Her bir tarama istasyonundan 360 derecelik yatay ve -60/90 derece aralığında dikey görüş alanından elde edilen nokta bulutları ilk başta karmaşık ve düzenli olmayan veriler yumağı halindedirler (Şekil 1).

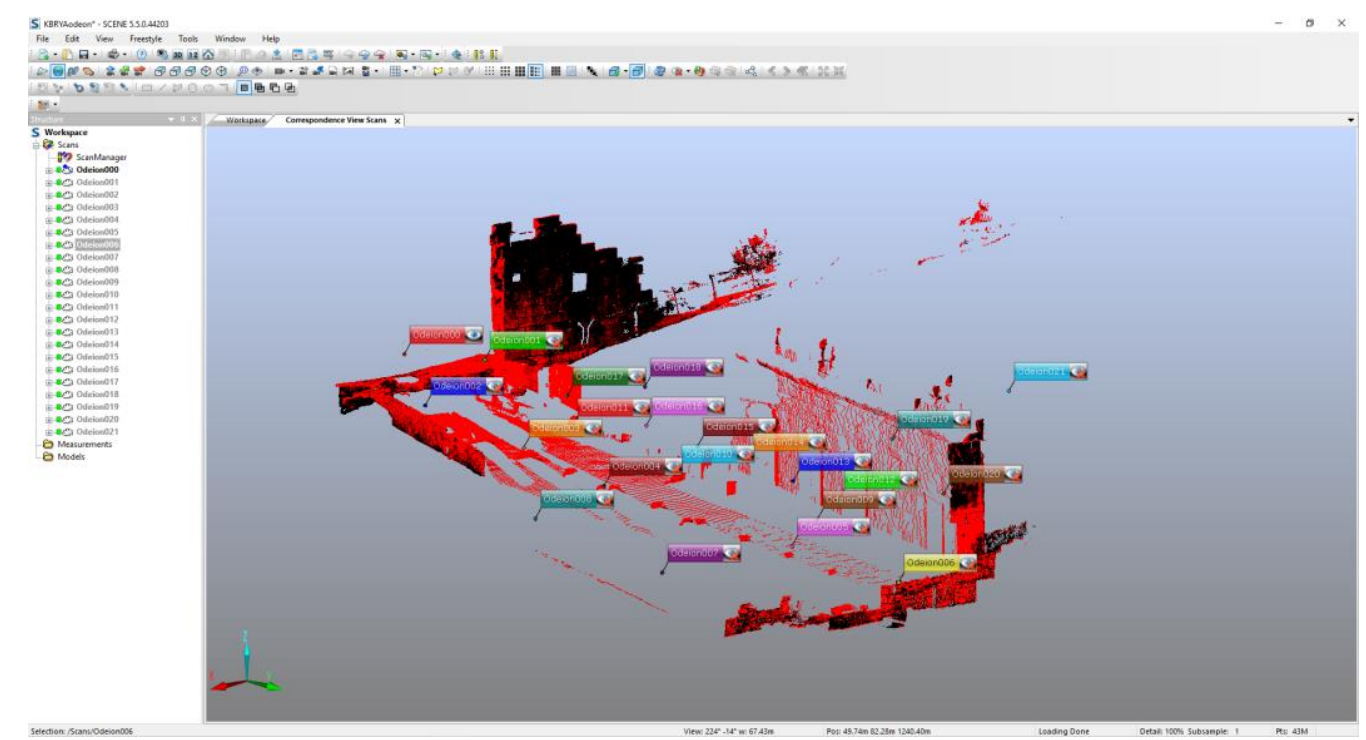

Şekil 1. Bir tarama istasyonundan elde edilen nokta bulutları

Farklı okuma istasyonlarından elde edilen nokta bulutlarının daha önce bahsedilen faro referans küreleri yardımıyla Scene yazılımı içerisinde birleştirilmiş ve böylelikle farklı okumalardan elde edilen yüzeyler üst üste çakıştırılmıştır (Şekil 2). Buradaki en önemli nokta birleştirme yapılırken elde edilen hassasiyettir. Çalışmamız sırasında istasyon sayısının fazla tutulması, birleştirme işleminde kullanılan referans kürelerinin ardışık taramalarda ortak olarak kullanılması hata payı$\mathrm{nı}$ son derece azaltmıştır. Farklı istasyonların nokta bulutlarının birleştirilmesi sonucu yaklaşık olarak 60 metre mesafede 0.0017 metre hata payı elde edilmiştir. Bu hata payının sıfıra yakın olduğu düşünülmektedir. 


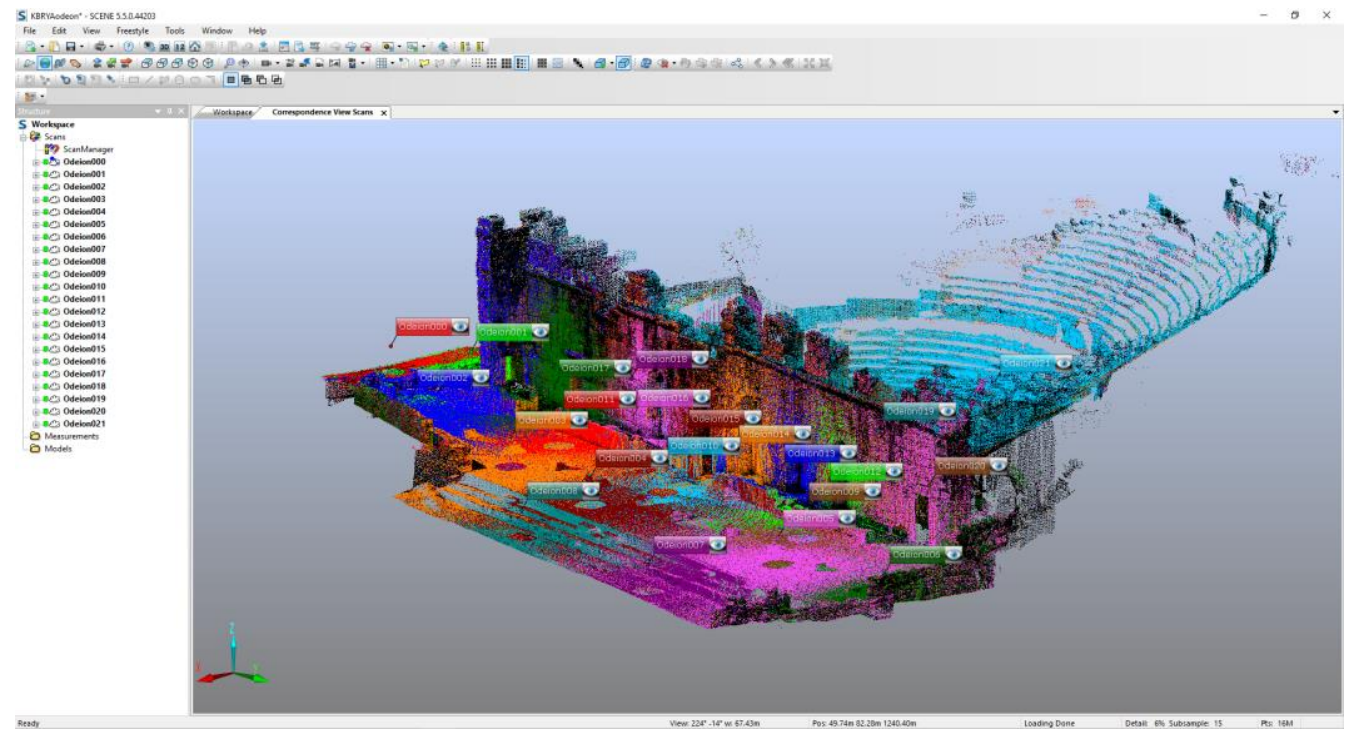

Şekil 2. Farklı okumaların birleştirilmesiyle elde edilen yüzeyler

Nokta bulutlarının birleştirilmesi ile yapının üç boyutlu modeli elde edilmiştir. Birleştirilen nokta bulutlarının üzerine lazer tarayıcı tarafından çekilmiş fotoğraflar giydirilerek yapının gerçekçi üç boyutlu modellemesi tamamlanmıştır (Şekil 3 ve Şekil 4). Elde edilen model farklı açılarda görüntülenebilmekte ve istenilen doğrultan kesit alınabilmektedir. Rölöve çizimlerine esas olmak üzere Faro Scene yazılımı üzerinde $300 \mathrm{dpi} \mathrm{çözü-}$ nürlükte ön görünüşe ait orthophoto olarak tabir edilen cephe görünüş resmi alınmıştır (Şekil 5 ve Şekil 6). Daha sonra bu orthophoto Autocad programına "raster image" olarak import edilerek resim üzerinden cephe çizimi yapılmıştır (Şekil 7). Alınan görüntülerinin gerçeğe uygunluğunun görsel olarak kıyaslanabilmesi için tarama yapılan kısımlardan bazılarının dijital kamera ile çekilmiş görüntüleri Şekil 8 ve Şekil 9'da verilmiştir.

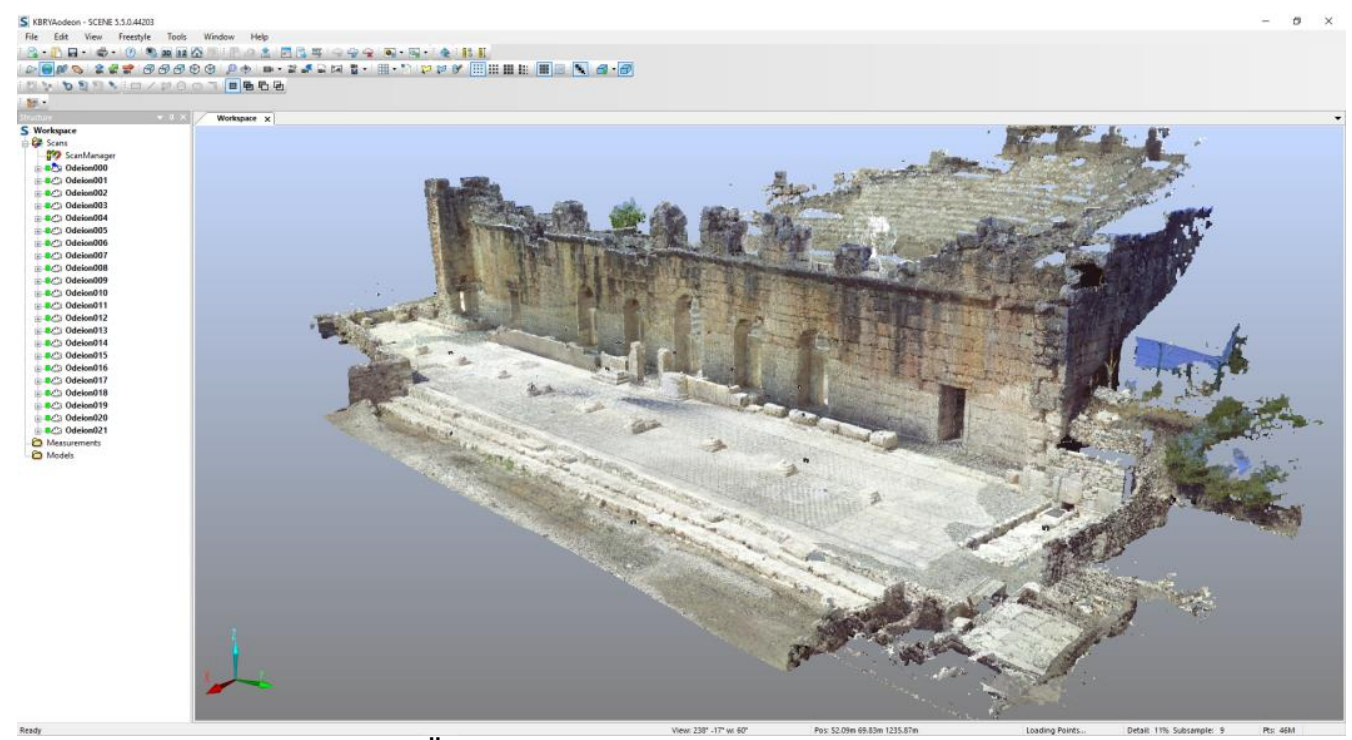

Şekil 3. Üç boyutlu modelleme (Faro Sceen verisi) 


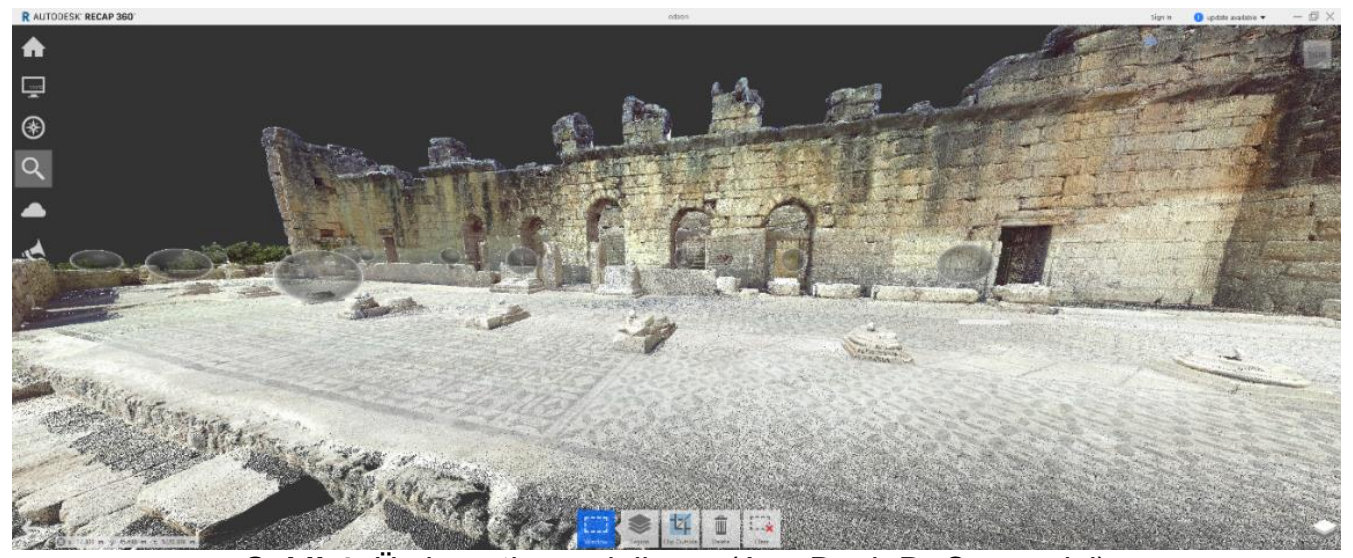

Şekil 4. Üç boyutlu modelleme (AutoDesk ReCap verisi)

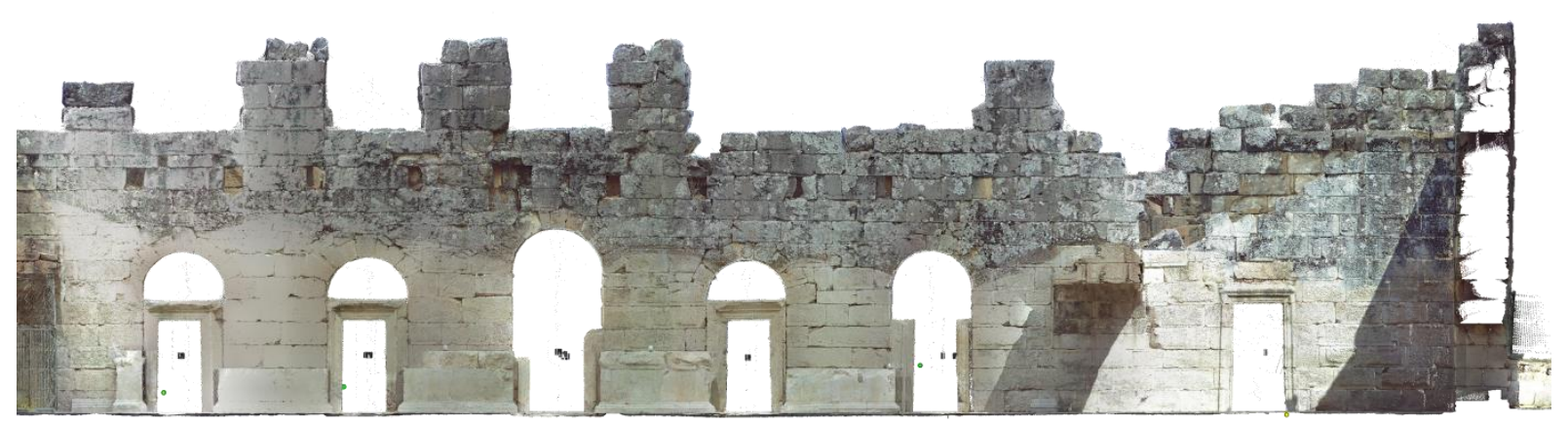

Şekil 5. Duvar orthophoto resmi (İç yüzey)

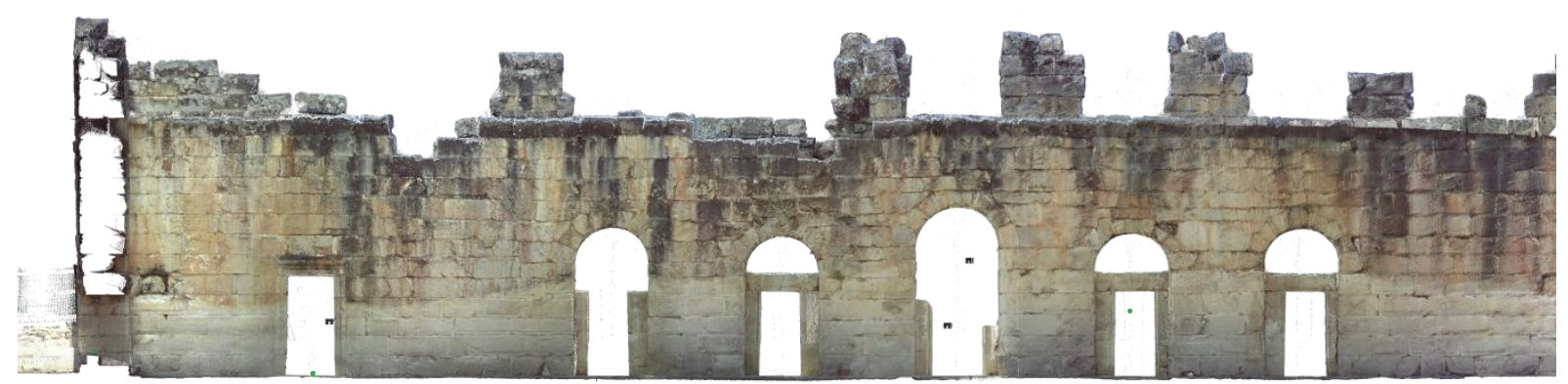

Şekil 6. Duvar orthophoto resmi (Dış yüzey)

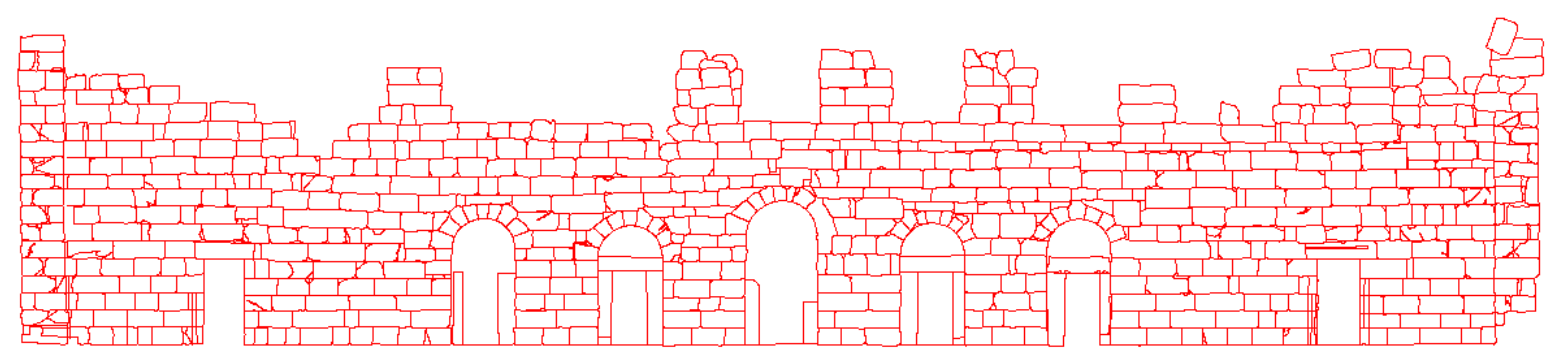

Şekil 7. Duvar dış yüzey çizimi (Autocad) 


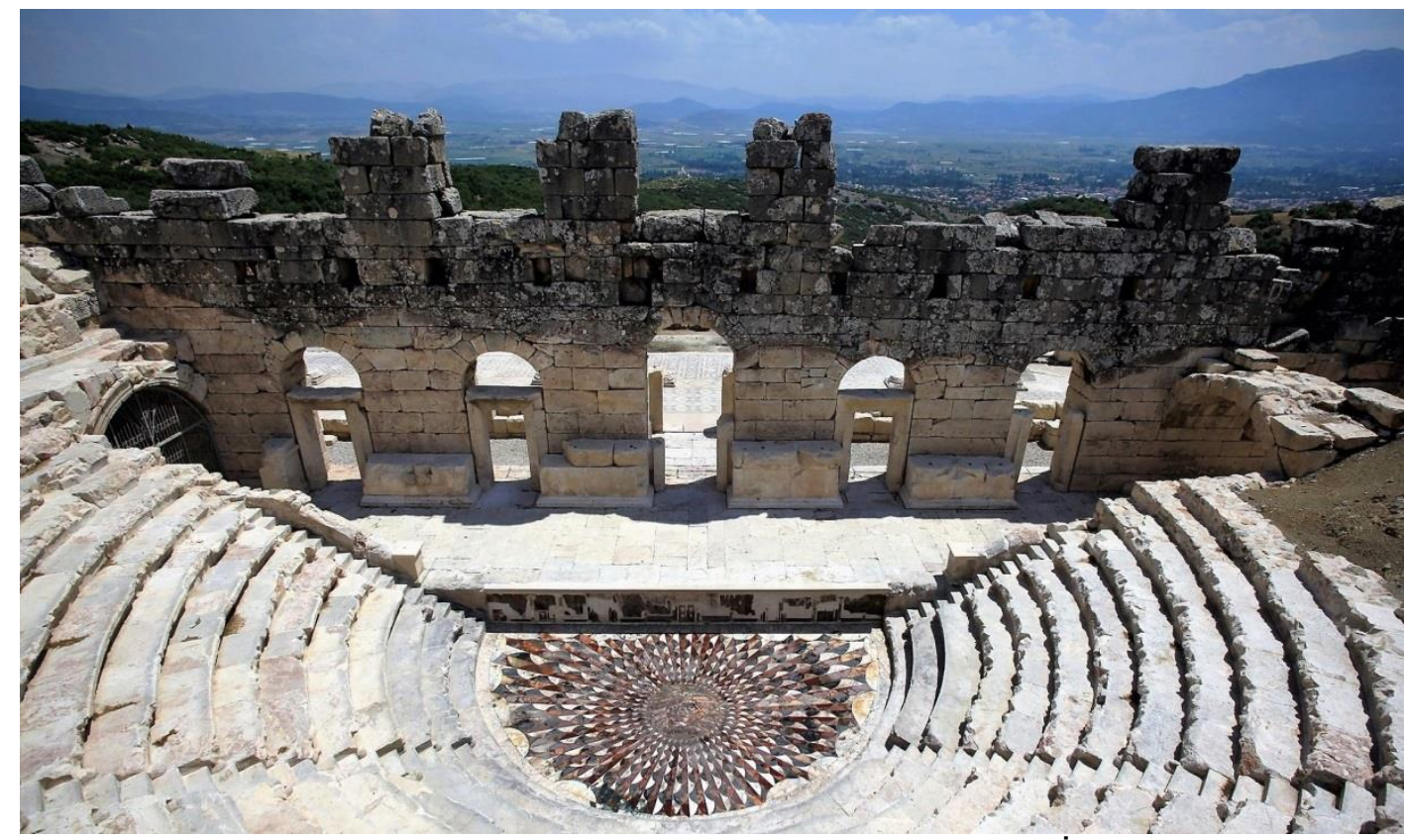

Şekil 8. Odeon sahne duvarı dijital kamera görüntüsü (lıç yüzey)

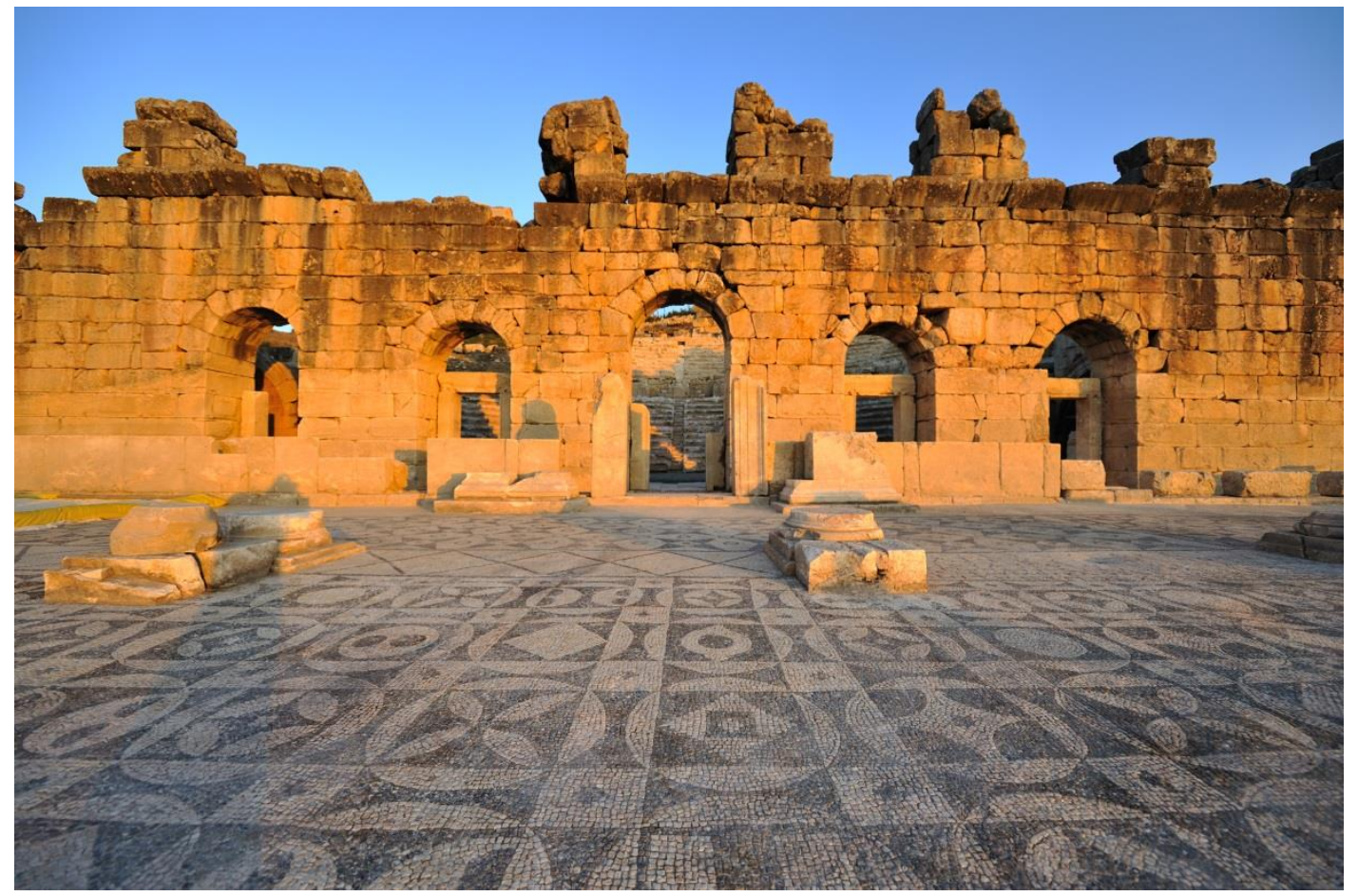

Şekil 9. Odeon sahne duvarı dijital kamera görüntüsü (Dış yüzey)

\section{SONUÇLAR}

Klasik yöntemler yıllarca restorasyon projelerinde ve arkeolojik çalışmalarda kullanılmıştır. Klasik yöntemde kullanılan ölçü aletlerinin hata yapma riskinin büyüklüğü, bu yöntemlerin uzun zaman alması çoğu zaman yapıların gerçekçi bir rölöve çizimine imkan sağlamamakta ve sağlıklı sonuçlar elde edilememektedir. Buna rağmen restorasyon projelerinin vazgeçilmez unsuru olan rölöveler klasik yöntemlerle ile çizilmiştir. Bu çalışmada da görüldüğü üzere lazer tarayıcılar ile aynı çalışmalar yapılabilmekte olup klasik yöntemlere göre daha hızı, daha kolay ve doğruluk payı yüksek bir şekilde rölöve çizimleri gerçekleştirilmiştir. Lazer tarayıcıların tarama maliyetle- 
rinin yüksek olması ve bu teknolojiyi kullanabilen yetkin personel sayısının azı̆ı̆ı bu yöntemin dezavantajı olarak görülse de sonuçlar bakımından bu teknolojinin kullanılması oldukça sağlıklı sonuçlar vermektedir.

\section{KAYNAKLAR}

Boehler, W., Marbs, A., (2002). 3D Scanning Instruments, ISPRS Commission 5 Symposiums, 2-6 September, Corfu, Greece
Ekinci, H.A., Özüdoğru, Ş., Dökü, E., Tiryaki, G., (2006). Kibyra Kazı Çalışmaları 2006 Excavations at Kibyra in 2006

URL-1 (2017). http://www.golhisar.bel.tr/3/33/golhisar/kibyraantik-kenti/ (Erişim Tarihi: 13.08.2017)

URL-2 (2017). http://www.arkeolojikhaber.com/haber-kibyraantik-sehri-orenyeri-776/ (Erişim Tarihi: 13.08.2017)

URL-3 (2017). http://whc.unesco.org/en/tentativelists/state=tr (Erişim Tarihi: 13.08.2017)

URL-4 (2017). http://www.ozrestorasyon.com/3d-tarama (Erişim Tarihi: 13.08.2017) 